\title{
Partnering Project Success Criteria in Malaysia
}

\author{
Hj. Kamaruzaman Jusoff \\ Yale University, Yale's School of Forestry \& Environmental Studies \\ 205 Prospect St, New Haven, CT 06511-2104, USA \\ Tel: 203-676-7761Ｅ-mail: kjusoff.kamaruzaman@yale.edu
}

Hamimah Adnan \& Nurul Fatanah Nazli

Faculty of Planning, Architecture and Survey

Universiti Teknologi MARA

Shah Alam Selangor, Malaysia

Tel: 60-3-5544-4935 E-mail: hamimah689@salam.uitm.edu.my

\begin{abstract}
Partnering is used as an approach in the procurement system as it could lead towards improving the performance of the construction industry. Organizations which used the partnering approach in their past construction projects are now reporting favorable results, which include decrease in project costs, delivery of project to program, time quality and buildability. Despite these benefits, there remain are still risks associated with this mode of procurement. Risk management process and partnering are critical to the succession of the construction project. Three (3) case studies were looked into to support this study. The opinions and techniques of risk mitigation were gathered. It was found that the most critical construction partnering risk is the partner's financial resources, the clients' problems and economic conditions and financial problems with one of the partner. It is hoped that the risk management programme will help to reduce such risks.
\end{abstract}

Keywords: Succession, Risk management, Partnering, Malaysian, Construction industry

\section{Introduction}

Partnering is an arrangement where the players are encouraged to work efficiently together. All parties in a construction project work together in an environment of trust and openness towards the efficiency of the project without conflict. Partnering has been popularly used as a procurement method since the Latham "Construction the Team" report was published (Latham, 1994). The report recommended partnering as a means of improving inter-firm relations. It is one of several strategies being proposed by practitioners, academics and managers (Cook and Hancher, 1990) and draws heavily upon lessons from Japanese manufacturing. Organisations which have used partnering for construction projects are now reporting favourable results, which include the decreased costs, quality improvement and delivery of project to programme. Partnering is becoming increasingly well understood in the building industry as a way of working with clients to jointly deliver vastly improved construction performance.

Partnering is a management approach used by two or more organisations to achieve specific business objectives by maximising the effectiveness of both parties. The approach was based upon mutual objectives, an agreed method of problem resolution and active search for continuous measurable improvements (Reading Construction Forum, 1995). It is only recommended where the management teams of all parties involved display a fundamental commitment to partnering and where companies share a common culture (Smircich, 1985). The partnering process involves allocating time to agreed objectives, establishing an open style of communication, developing a mechanism for problem resolution and identifying measures designed to monitor and help improve performance (CIB, 1997). It attempts to create an environment where trust and teamwork prevent disputes, foster a co-operative bond to everyone's benefit and facilitate the completion of successful project. Organizations which have used partnering for construction projects are now reporting favorable results, which include decreased costs, improved quality and delivery of project to program. This management concept attempts to prevent issues such as the dissatisfaction of a customer or contractor filing a claim and in most cases, it can be traced back to issues related to the three C's - communication, coordination, and conflict management. It is a planned effort by all stakeholders of a construction project to establish an environment of mutual trust, open communication, cooperation, and teamwork to encourage everyone to succeed by achieving mutually agreed upon goals and objectives. 
Risk is a function of the interaction of uncertainty and the magnitude of the potential loss or gain. Construction work involves risks due to the complex nature and uncertainties inherent in the construction process. Consequently, the construction industry suffers due to several factors, which act as barriers of a partnering approach to procurement. The client, consultants, contractor and sub-contractors of a construction project all have a role to play in delivering quality project. Failure by any party will seriously affect the quality of the final project. Risk management is a discipline to protect the asset, reputation and profits of the partnering method by reducing the possible losses or damages before they occur. It works with risk analysis and assessment to ensure proper financing controlled. In order to mitigate the risks in partnering projects, it is essential that management practitioners need to develop proven technique such as risk simulation techniques. The construction industry is plagued with by risk (Flanagan and Norman 1993), but often not dealt adequately, resulting in poor performance with increased cost and time delays (Thompson and Perry 1992). Construction projects are becoming increasingly complex and dynamic in their nature and the introduction of new procurement methods means that many contractors have to rethink their approach to the way risks are treated within their projects and organizations. The Malaysian construction industry is a conglomeration of diverse sub-industries loosely lumped together as a sector of the economy. The industry is primarily concerned with building and civil engineering, and its main activities relate to the planning, regulation, design, manufacturing, construction, fabrication and maintenance of buildings, infrastructure facilities and process plant. The building sector of the industry encompasses the construction of commercial, industrial and housing (high, medium and low-cost) projects; infrastructure facilities includes the construction of roads and highways, drainage, sewerage, industrial structures, dams and water retaining structure projects; whilst process process-plant construction ranges from sewerage, water treatment, energy to fertilizer and food projects.

Malaysia has a fast developing economy with a growing population. Since independence in 1957, the economy has expanded from a predominantly agriculture to a broad-based economy, diversified into manufacturing, oil and gas, tourism and heavy industries. The industry is the vital sector that has enabled the government to facilitate this change. It is of enormous economic and social significance as it continues to provide the impetus for stimulating development and growth. It provides and maintains the much needed infrastructure facilities for the growing population, and forms the base for the other segments of the industry to function. The construction of buildings, and infrastructure facilities such as roads and highways, leads to the creation and growth to new township and industrial zones. The transportation network, which links these newly developed areas, further opens up rural areas surrounding these areas. This in-turn promotes economic growth, employment and social activities within these regions. The issue arising in this paper is regarding risk factors associated in construction Partnering. Risks constitute a barrier to the successful adoption of this procurement method in construction and one needs to come out with risk management techniques although formal risk analysis and management techniques are rarely used due to lack of knowledge and doubts on their suitability in construction industry activities. The aim of this research is therefore to identify effective risk management measures applied to mitigate the risks faced by the construction industry using the partnering procurement method.

\section{Research methodology and data analysis}

Case studies were conducted based on the risks associated within partnering project and the effective risk management measures used to mitigate the risk. Case studies were conducted based on various construction companies' registered under the Malaysian Construction Industry Board (CIDB). For the purpose of this research, the researcher had examined and conducted three (3) projects implemented by Contractor AXA, BXB and CXC to determine the problems and the most effective management of risk applied in each of the projects. The succession criteria accounted for in Partnering projects are based on whether the projects are within budget and profit, whether they cater to the client satisfaction and goodwill if they are on/ahead of schedule, of quality standard and whether they enhance the partner reputation and if they meet up to the team's satisfaction. The main characteristics of the three cases are summarized in Table 1.

$<$ Table 1: Main Characteristics of Partnering Cases $>$

\subsection{Case Studies}

\subsubsection{Case Study 1: Civil Works}

The project was a civil engineering work which involved excavating, deepening, straightening the alignment of the river and building a slope protection. The client was a local government organization responsible for maintaining the river in Malaysia. The partner, hereafter referred to as DD, was a construction company. Company AXA acted as the other partner company and the Partnering is hereafter referred to as AXA - DD Partnering. The share distribution between AXA and D was to be $70 \%$ and $30 \%$ respectively. After the project was awarded in October 2000, problems slowly emerged. The project was stagnant due to financial problems in DD. The project was far behind schedule and the work was of poor quality. The client was dissatisfied and the relationship between the partner and the client deteriorated. Serious negotiations were then held among the directors from the two parties and they agreed that the project would not continue in the same manner. The project was beyond the financial capability of DD as DD was undertaking other 
projects at the same time with lacked in sufficient capital limited workforce and equipment. It was decided that Company AXA would take over the entire project and thereafter DD was terminated.

\subsubsection{Case Study 2: Building Works}

Company BXB entered into Partnering with EE on a Design and Build basis with both companies holding 75: 25 shares respectively. The project was divided into two parts in which Company BXB was responsible to construct the main hospital building while EE contractor was responsible for the construction of staff accommodation. This was done to ensure undisrupted operations. Although, disagreements between the staff surfaced occasionally, they were resolved as they arose between the parties involved. The progress was satisfactory and this project was expected to finish within the allocated budget and time.

\subsubsection{Case Study 3: Building Works}

This Partnering was formed by CXC and FF that has a strong record in the construction market, particularly in the field of building, civil works and infrastructure. Each partner held joint and individual responsibility for the partnering work and would accept the loss or profit according to their shares. The share distribution of CXC and FF was 60: 40 respectively. The contract was based on the Public Works Department Form as conditions of contract. This project ran smoothly and by April 2006 the project was at the end stage. The cost was expected to be within budget and the completion of the project would be on time. All partners were satisfied with this alliance. The interview regarding the case studies was based on eight (8) risk management measures which consist of: (1) Partner Selection; (2) Agreement; (3) Sub-contract; (4) Engineering Contract; (5) Employment; (6) Good relationships; (7) Control and; (8) Others. The risk management process must go through (1) Identification; (2) Analysis; and (3) Control.

The risk management process to identify the risks is based on the sources of the risks which are categorized into three groups: (1) Internal; (2) Project-specific; and (3) External. Under these groups there are several factors associated within the Partnering. These most critical factors are analyzed during three stages of Partnering: (1) Start-up (2) Operation; and (3) Dismantle. Once a risk is identified and defined, it becomes a management problem (Flanagan and Norman, 1993).

\subsection{Analysis of risk mitigation measures}

Risk management must be carried out as earliest as possible to mitigate any negative impact on the project's progress and profitability. In the early stage of a Partnering, selecting a suitable partner, drafting a good agreement, formulating correct personnel policies and adopting a suitable operational structure are the most effective management measures for future risk avoidance or mitigation. The first step towards the risk management process is risk identification, which may consist of the systematic and continuous task of identifying, classifying and assessing the importance of project risks. The identification of risks and the creation of a risk list are dependent upon many factors such as past experience, personal tendency and possession of the information. The aim is to generate a comprehensive list of the relevant risks and to document what each one involves. For these case studies, the researchers had classified the risk factors into three main groups.

\section{Results and discussion}

\subsection{Internal risk factor: Partner's Financial Resources and Managerial Competence}

In Case Study 1, the most critical factor affecting the Partnering was the financial problem with DD contractor. The financial status of DD contractor was at critical stage. This was happened because at the same time DD contractor was taking on other projects. This could be labeled as lack of management competence and resource. The result was the project was far behind schedule and the workmanship of low quality.

\subsection{Risk analysis}

For the three case studies, the researchers had analyzed the risk factors identified in each project into three stages which consist of: start-up, operation and dismantle. The researchers found that the internal risk factors in Case study 1 falls into the Operation Phase. In the operation phase, the partner had a large numbers of issues pertaining to financial status and responsibility. Conflicts arose during the execution of project. The conflict was unavoidable and this had a negative impact on the Partnering performance.

\subsection{Risk Control/Treatment}

An interview was conducted based on the previous questionnaire. A summary of the important measures are shown in Table 2 in which the researcher believe the person involved in the three case studies had taken in order to mitigate the risks in their Partnering project.

$<$ Table 2 Risk Mitigation Measures $>$ 


\subsubsection{Partner selection}

Partner selection for a Partnering is a risk in itself becaus Risk Mitigation Measures e is directly affects the outcome of the Partnering. Essentially, the company should analyze the various attributes of the potential partners and choose one that can complement them most in terms of needs. Companies usually search for partners who have compatible objectives, who are experienced in Partnering projects, specialize in technical skills with suitable management styles and are trustworthy and financially credible. Companies with existing relationship with each other may find it easier to form a Partnering. In the three cases, the companies of AXA and BXB (Case 1 and 2), BXB (Case 2) and CXC- FF (Case 3) had strong financial capabilities. In addition to financial aspects, management competence and complementary skills are essential ingredients of prospective partnerships. In Case study 2 and 3, each of the partners was qualified technically in his respective area and was competent in management. A good relationship with the client is also important for the success of a project. The three projects in this research were developed by government agencies.

\subsubsection{Agreement}

Most of the researchers on partnering have concluded that a good Partnering agreement is an important success factor that can prevent a great deal of trouble and conflict in future partnering operations. A good Partnering agreement must be drafted in clear terms with conditions that can be easily understood by all partners as well as the working staff, and each partner's authority is well defined. In three cases, all parties regarded their agreement as clear and the scope was well defined. In Case 1 and 2, they made new agreement and it is being drafted well, bound and registered between the partners. All of the terms and conditions were recorded. The third cases were developed from the previous agreements used in successful Partnering. In terms of work distribution, the projects were broken into packages and works were allocated to the respective partners. In Case Study 1 the work for excavation, straighten, and deepening the river was split vertically into two parts between the partners. It is also the same for the second case study, whereby the works were divided into two packages which are constructing the hospital main building and staff accommodation. This allowed both partners to concentrate their resources and defined the works.

\subsubsection{Employment}

The characteristic of a successful staffing policy in Partnering is that the staff must be committed to the Partnering and unbiased towards different partners. In Case Study 1 and 2, the AXA - DD and AXA - DD contractors employed most of the staff from the local manpower market through advertisement. They chose their critical staff based on good qualifications, previous experiences and their good records in previous types of procurement or Partnering projects. All the staff involved in the three cases was encouraged by the directors to commit themselves to the Partnering. The other effective risk mitigation measure was to carefully organize the operation structure so that the responsibilities and rights of all the positions did not overlap. The probabilities of conflicts could be reduced as the staff could perform their work without unnecessary disturbances.

\subsubsection{Management Control}

One management style was adopted in the three cases it was controlled. In the three cases, the decision-making was given to the bigger shareholder. Nevertheless, discussions were made between the partners before any decisions were made. The other important factor was the allocation of work between partners. In Case 2, the work was divided into two parts, in which AXA was responsible for the construction of hospital main building while BXB had to construct staff accommodation. The scope of works was managed by each party independently. The employees from both parties had limited contact with each other and this subsequently reduced conflict.

\subsubsection{Sub-contracting}

Sub-contractor selection is very critical for the success of a construction project. Much research work has been conducted to study the relationship between the main contractor and their sub-contractors. Setting up a strategic alliance with sub-contractors was recommended by Kwok and Hampson (1997). For Case 1 and 2, the sub-contractors and suppliers were from the local Malaysian market. The agreement was between each partner and their sub-contractors. Their services were obtained through advertisement done by each partner. Unfortunately, the co-ordination within D contractor became difficult and progress was not achieved for the project. That was one of the main causes for the initial failure of this Partnering project. In case 3, CXC owned several sub-contractors and they had a good relationship for a long period of time with the parties' parent companies.

\section{Conclusion}

The analysis of the risk mitigation measures have shown that the risk management model could be a useful process for implementing a successful construction Partnering. The critical risk factors must be systematically studied from the internal perspective, Project-specific, and External risk groups in combination with the Partnering development stages. The three case studies show that the important measures must be adopted when a company decides to enter into Partnering. It must consider the local partner's financial and management capability, it must insist on a good drafting of 
Partnering agreement that clearly defines each partner's responsibility and liability. It is also necessary to ensure that critical staffs are unbiased and experienced in joint management. It is preferable to adopt a one-partner-dominant style of management where one partner is capable enough to handle major construction works. It is critical for the partner to choose experienced and familiar sub-contractors and suppliers to strengthen the Partnering operation.

The risks of Partnering are different in each project involving different participants. However, the most critical factors exist in the financial aspects of Partnering, government policies, economic conditions and project relationships. Although formal risk management has not yet been implemented in most cases or projects, the efforts of the construction personnel in a Partnering project to respond to risks by means of training and education with the risk model provider is the best way of understanding the importance of risk management.

\section{References}

Construction Forum. (1995). Trusting the Team: The Best Practice Guide to Partnering in Construction,' Centre for Strategic Studies in Construction, Reading University.

Cook, L and Hancher, D.E. (1990). Partnering Contracting for the Future, Journal of Management in Engineering.

Flanagan, R and Norman, G. (1993). Risk Management and Construction, Blackwell Publishing.

Kwok, T.L \& Hampson, K.D. (1997). 'Strategic Alliances Between Contractors and Subcontractors - A Tender Evaluation Criterion for the Public Work Sectors,' School of Engineering, Griffith University, Queensland.

Latham. (1994). Constructing the Team. Department of the Environment, pp. 14-85.

Smircich, L. (1985). 'Is the Concept of Culture a Paradigm for Understanding Organization and Ourselves,' Organization Culture.

Thompson, P \& Perry, J. (1992). Engineering Construction Risks - 'A Guide to Project Risk Analysis and Risk Management', Thomas Telford, London.

Table 1. Main Characteristics of Partnering Cases

\begin{tabular}{llll}
\hline Characteristics & \multicolumn{1}{c}{$\begin{array}{c}\text { Case Study 1 } \\
(\text { AXA-DD) }\end{array}$} & $\begin{array}{l}\text { Case Study 2 } \\
(\text { BXB - EE) }\end{array}$ & $\begin{array}{l}\text { Case Study 3 } \\
(\text { CXC - FF) }\end{array}$ \\
\hline Project Type & Civil Works & Building & Building \\
Location & Malaysia & Malaysia & Malaysia \\
Project Value & RM 98,000,000.00 & RM 170,000,000.00 & RM 230,000,000.00 \\
Project Duration & 3 Years & 3 Years & 1 Year 4 Month \\
Shareholding (\%) & $70: 30$ & $75: 25$ & $60: 40$ \\
Opening Structure & Integrated with local partner & Integrated with local partner & Integrated with local partner \\
\hline
\end{tabular}


Table 2. Risk Mitigation Measures

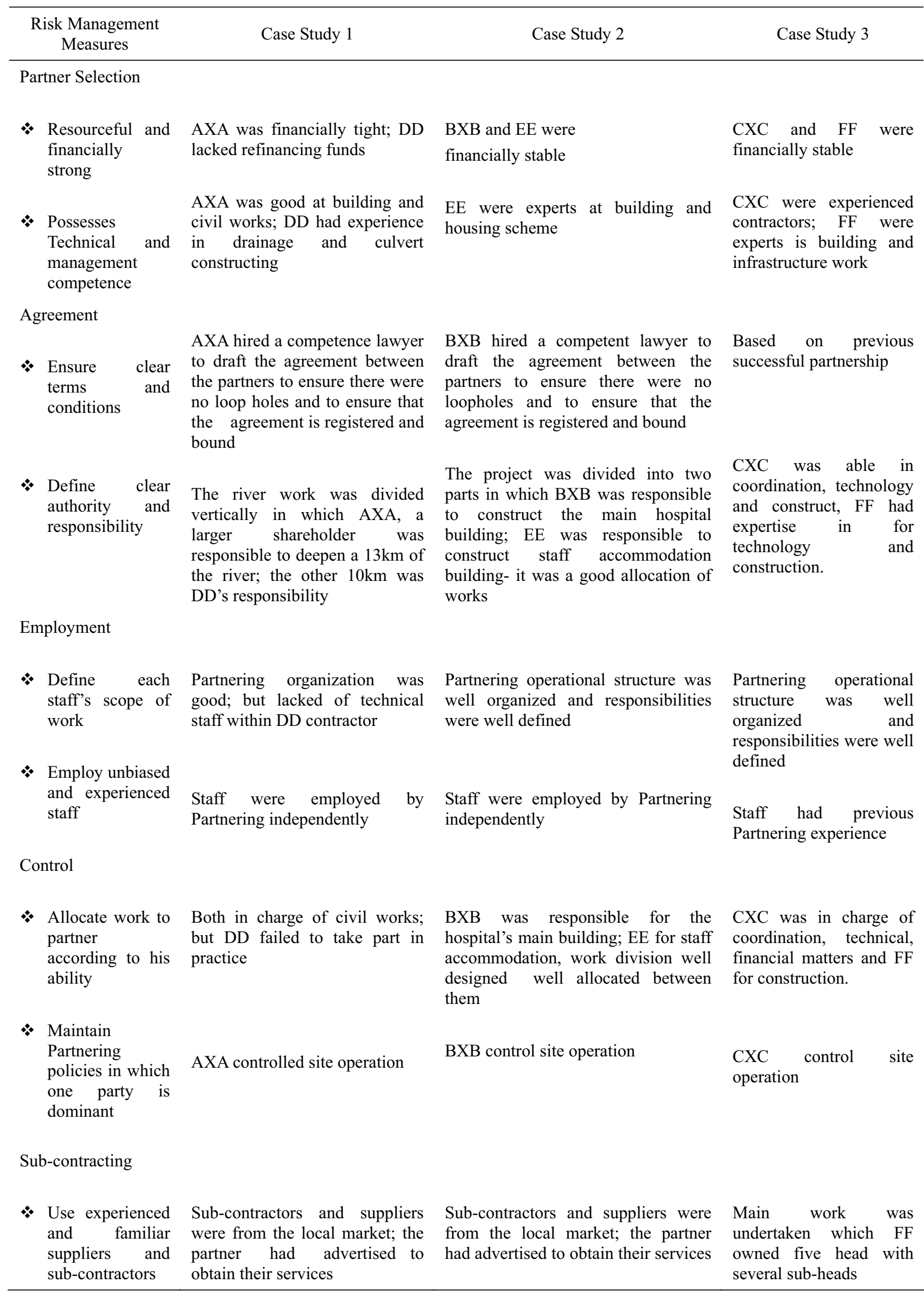

